\title{
ENSINO E APRENDIZAGEM NA VISÃO DO ESTUDANTE
}

\author{
ENSEÑANZA Y APRENDIZAJE EN VISIÓN DEL ESTUDIANTE
}

TEACHING AND LEARNING IN THE STUDENT VISION

\author{
Adelcio Machado dos SANTOS ${ }^{1}$ \\ Alexandre Carvalho ACOSTA ${ }^{2}$ \\ Everaldo da SILVA ${ }^{3}$ \\ Liz Barbara BORGHETTI ${ }^{4}$
}

\begin{abstract}
RESUMO: Muitos autores têm se debruçado sobre o tema ensino e aprendizagem, no entanto, poucos são os que deram vozes aos estudantes, protagonistas principais dessa relação. Esse artigo é parte de um trabalho de pesquisa realizado no Programa de Mestrado Interdisciplinar da Universidade Alto Vale do Rio do Peixe, tendo como análise a bibliografia de autores que tratam sobre o tema ensino e aprendizagem, bem como a percepção dos estudantes do Ensino Médio Integrado dos cursos de Eletroeletrônica, Informática e Agropecuária do Instituto Federal Catarinense (IFC), campus Videira-SC. A pesquisa foi realizada durante o primeiro semestre de 2016, tendo como foco os estudantes dos terceiros anos do ensino médio.
\end{abstract}

PALAVRAS-CHAVE: Educação. Ensino. Aprendizagem.

RESUMEN: Muchos autores han estado trabajando en el tema de la enseñanza y el aprendizaje, sin embargo, son pocos los que han dado voz a los estudiantes, los principales protagonistas de esta relación. Este artículo es parte de un trabajo de investigación llevado a cabo en el programa de la Interdisciplinario Maestro en el Alto Rio do Peixe Valle de la Universidad, con el análisis, la literatura de autores que se ocupan en la impartición de la materia y el aprendizaje, así como la percepción de los estudiantes secundarios Eletroeletrônica integrada de cursos, Tecnología de la Información y la Agricultura del Instituto Federal de Santa Catarina (CFI), el campus Videira-SC. La encuesta se llevó a cabo durante la primera mitad de 2016, se centra en los estudiantes de tercer año de secundaria.

PALABRAS CLAVE: La educación. Educación. El aprendizaje.

1 Universidade Alto Vale do Rio do Peixe (UNIARP). Docente e Pesquisador. E-mail: adelcio@ redelnet.com.br.

2. Universidade Alto Vale do Rio do Peixe (UNIARP). Mestrando no Programa Interdisciplinar em Desenvolvimento e Sociedade. Docente e pesquisador pelo Instituto Federal, Campus Videira-SC. Email: alexandre@alexandreacosta.com.

3 Universidade Alto Vale do Rio do Peixe (UNIARP). Professor e Pesquisador dos Programas de Mestrado Profissional em Educação Básica e Acadêmico Interdisciplinar em Desenvolvimento. E-mail: prof.evesilva@gmail.com.

4 Universidade Alto Vale do Rio do Peixe (UNIARP). Mestranda do Programa de Mestrado Interdisciplinar. E-mail: barbara.barbarab@hotmail.com.

RIAEE - Revista Ibero-Americana de Estudos em Educação, Araraquara, v.12, n.4 , p.2193-2209, out./dez. 2017. 
ABSTRACT: Many authors have focused on the subject of teaching and learning, however, few are those who gave voice to students, the main protagonists of this relationship. This article is part of a research work carried out in the Interdisciplinary Master's Program of the Alto Vale do Rio do Peixe University, having as an analysis the bibliography of authors dealing with the subject of teaching and learning, as well as the students' perception of High School Integrated in the Electronic Technology, Informatics and Agriculture of the Federal Institute of Santa Catarina (IFC), campus Videira-SC. The research was conducted during the first semester of 2016, focusing on the students of the third years of high school.

KEYWORDS: Education. Teaching. Learning.

\section{Introdução}

A construção do conhecimento passa pelo processo de ensino e aprendizagem. Perpassa por esse caminho a evolução continuada das capacidades cognitivas dos seres envolvidos. A aprendizagem é fundamental para que o sujeito desenvolva habilidades que lhe auxiliem na transformação ou compreensão da sociedade em que vive.

Desse modo, o professor possui um papel fundamental na educação formal, pois é ele quem irá instigar o estudante a construir o saber. Freire (2011) destaca a importância do professor estar atento para a curiosidade do estudante, indicando que a partir da curiosidade o sujeito é capaz de produzir ou fomentar o conhecimento.

Como professor devo saber que sem a curiosidade que me move, que me inquieta, que me insere na busca, não aprendo nem ensino. [...] Com a curiosidade domesticada posso alcançar a memorização mecânica do perfil deste ou daquele objeto, mas não o aprendizado real ou o conhecimento cabal do objeto. A construção ou a produção do conhecimento do objeto implica o exercício da curiosidade, sua capacidade crítica de "tomar distância" do objeto, de observá-lo, de delimitá-lo, d23e cindi-lo, de "cercar" o objeto ou fazer sua aproximação metódica, sua capacidade de comparar, de perguntar (FREIRE, 2011, p. 83).

A escola precisa ser vista como um ambiente onde a construção social do indivíduo também esteja na pauta, de modo que o professor se envolva como o mediador do conhecimento, não apenas o transmissor. Isso já foi destacado por Franco (2008), no sentido de superação dos conceitos de que o aluno é apenas um receptor do saber, para passar a tê-lo como agente histórico que transforma e é transformado, na interação com a sociedade:

No plano de entendimento dos processos de ensino-aprendizagem,

RIAEE - Revista Ibero-Americana de Estudos em Educação, Araraquara, v.12, n.4 , p.2193-2209, out./dez. 2017. 
deve este pedagogo superar a concepção de um sujeito que absorve o aprendizado, para caminhos de um aprendiz que constrói significados e novas relações com o mundo circundante, pressupondo a educação como uma prática social, emergente da configuração dialética dos contextos sociais. O homem deverá ser interpretado como sujeito histórico a interagir com suas condições existenciais, modificando-as e sendo por elas transformado (FRANCO, 2008, p. 110).

A ideia de Arroyo (2011, p.53), é a de superarmos a simples forma de ver o aluno como uma conta bancária e notarmos ele(a) como um sujeito que possui angústias, problemas, ideias, sonhos, enfim, que pode alterar seu modo de ver o mundo em que vive, assim como ser um agente dessa mudança a partir de uma visão mais aprimorada sobre a sociedade em que está inserido. Sobre a humana docência, o autor ressalta:

No convívio com a infância popular percebemos que algo falta em nosso ensinar, que esperam mais de nós e de seu tempo de escola, um tempo tão difícil de segurar diante das pressões da sobrevivência. Descobrimos os educandos, as crianças, os adolescentes e jovens como gente e não apenas como alunos. Mais que contas bancárias, onde depositamos nossos conteúdos. Vendo os alunos como gente fomos redescobrindo-nos também como gente, humanos, ensinantes de algo mais do que nossa matéria. Fomos relativizando os conteúdos, repensando-os e selecionando-os em função dos educandos, de sua formação, de sua educação. Nesse processo de redefinir o saber escolar, as funções sociais, políticas e culturais da escola em função de projetos de sociedade e de ser humano, de cidade e de cidadania não perdemos a centralidade nem do conhecimento, nem do nosso ofício de ensinar.

A troca de experiências entre estudantes e professores experimentada no ambiente escolar são mais ricas quando o assunto envolve o contexto em que o estudante está inserido.

\section{Relação professor e aluno}

A desmistificação do professor enquanto "detentor do saber", fará com que o discente sinta-se mais à vontade para questionar, se envolver e participar do assunto em discussão.

Em um ambiente onde a liberdade de questionamentos para sanar dúvidas é inexistente, praticamente não existe a participação do aluno no processo de ensino e de aprendizagem, ficando o professor como o detentor do saber, sem saber se há dúvidas e/ou compreensão por parte dos seus ouvintes. 
A pesquisa indagou os alunos para saber sua visão sobre essa relação, indicando quatro possibilidades de respostas, onde perguntou-se: 'As boas relações professor/aluno (diálogo, respeito, atenção...), em sala de aula': 1. Não interferem nos processos do ensino e da aprendizagem? 2. Contribuem significativamente para que o aluno aprenda melhor? 3. Representam um fator determinante nos processos do ensino e da aprendizagem? 4. Constroem um ambiente de liberdade e de confiança para tornar possível a retomada de conteúdos não assimilados.

As respostas, embora divididas, não conferiram a possibilidade de não haver interferência na relação professor/aluno, o que significa afirmarmos que o estudante percebe a importância do bom relacionamento com o professor no processo de ensino e de aprendizagem, conforme pode-se verificar no Gráfico 1.

Gráfico 1: Relação entre professor/aluno, na concepção dos alunos.

\section{As boas relações professor/aluno (diálogo, respeito, atenção...) em sala de aula:}

$0 \%$

Fonte: Elaboração própria a partir de dados da pesquisa. 
Percebe-se nesta questão que o estudante está atento para o relacionamento com o professor, sendo que nenhuma resposta contemplou a primeira alternativa, que sugeria que a relação professor/aluno não interfere nos processos de ensino e da aprendizagem.

Diante dessa percepção, o questionário previa saber o que os estudantes pensam sobre a relação que estão tendo com seus professores, dividindo-as entre boas, regulares, deficitárias e ruins, com as seguintes observações: 'Boas: todos os professores mantêm um bom relacionamento com os alunos; Regulares: poucos são os professores que mantêm boas relações com os alunos; Deficitárias: periodicamente ocorrem episódios de desentendimentos e incompreensões entre professores e alunos, dificultando os processos do ensino e da aprendizagem; Ruins: representam o fator que mais contribui pelo baixo rendimento dos alunos.

Os resultados são apresentados no Gráfico 2.

Gráfico 2: Relação professor/aluno, na concepção dos alunos.

\section{É possível afirmar que as relações professor/aluno que estão ocorrendo em sala de aula, são:}

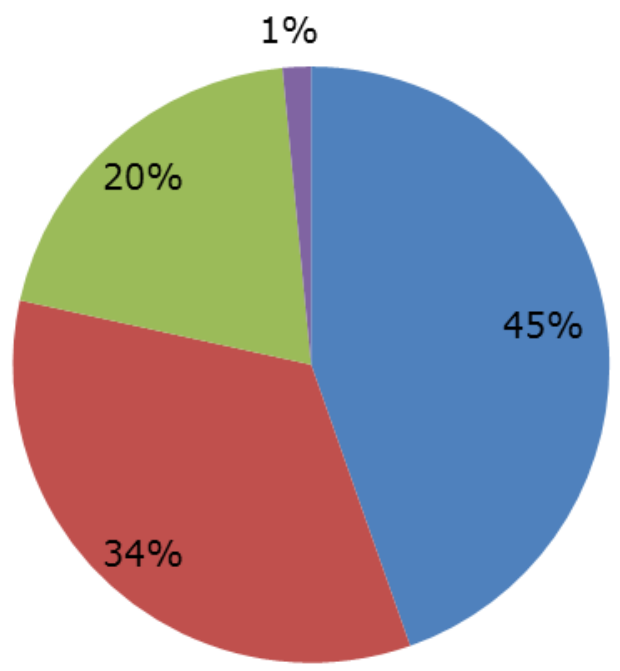

Fonte: Elaboração própriaa partir de dados da pesquisa.

Neste contexto, $45 \%$ dos entrevistados afirmam que a relação com os professores é boa junto aos alunos, e 54\% afirmam ser regulares ou deficitárias, o que 
demonstra uma preocupação por parte dos estudantes com relação ao relacionamento com os professores.

\section{Desenvolvimento do conhecimento}

O desenvolvimento humano, na perspectiva descrita por Bronfenbrenner (1992 apud POLONIA; DESSEN; SILVA, 2005, p. 74), é uma tentativa de embasamento sociológico e psicológico, isto é, o desenvolvimento ocorre associado às mudanças ou à estabilidade biopsicológica do ser humano ao longo de sua vida. Para os autores, sobre essa teoria, existe uma inter-relação mútua entre os fatores biológicos, psicológicos e ambientais:

Portanto, o desenvolvimento humano se estabelece de maneira contínua e recíproca, no interjogo entre aspectos biológicos, psicológicos, e ambientais, em que as forças que produzem a estabilidade e a mudança nas características biopsicológicas da pessoa durante sucessivas gerações, são percebidas considerando os processos evolutivos e as transformações operadas na pessoa e no seu ambiente (POLONIA; DESSEN; SILVA, 2005, p. 74).

O desenvolvimento do conhecimento vai estar diretamente ligado à interação existente ou não entre professor e estudante. $\mathrm{O}$ desenvolvimento humano ocorre em uma relação próxima e entre os processos que agem no ser humano e os que atuam no ambiente, provocando mudanças tanto na pessoa como no ambiente em que esse está inserido. A teoria de desenvolvimento bioecológico de Bronfenbrenner considera que a genética e o ambiente são aliados e não inimigos na evolução da aprendizagem humana. Os fatores genéticos e ambientais interagem e resultam na evolução do processo de desenvolvimento.

$\mathrm{Na}$ pesquisa, observou-se que quase $50 \%$ dos estudantes entrevistados afirmam que a explicação oral ainda é a forma de melhor absorção do conhecimento. Embora não possamos deixar de expor o segundo posto da pergunta, onde $36 \%$ dos entrevistados indicam a leitura como forma de aprenderem mais sobre os conteúdos abordados. Temos assim uma opinião dividida, que pode significar a presença de novas formas de aprendizagem, já sendo vistas pelos estudantes como melhores que a maneira tradicional.

Segundo Tardif (2012, p. 139), quando o aluno se sente acolhido, respeitado, também retribuirá ao professor com a mesma consideração, não sendo necessária ao

RIAEE - Revista Ibero-Americana de Estudos em Educação, Araraquara, v.12, n.4 , p.2193-2209, out./dez. 2017. 
professor a utilização de métodos desumanos: "No tocante ao professor, a autoridade reside no respeito que ele é capaz de impor aos seus alunos, sem coerção. Ela está ligada ao seu papel e à missão que a escola lhe confere, bem como à sua personalidade, a seu carisma pessoal." O papel principal do professor é desenvolver a aprendizagem do aluno. Não podemos negar que nessa relação do ensino e da aprendizagem existe uma troca.

A respeito do conceito de autoridade, Arendt (2000, p. 129) explica:

Se a autoridade deve ser definida de alguma forma, deve sê-lo, então, tanto em contraposição à coerção pela força como a persuasão através de argumentos. (A relação autoritária entre o que manda e o que obedece não se assenta nem na razão comum nem no poder do que manda; o que eles possuem em comum é a própria hierarquia, cujo direito e legitimidade ambos reconhecem e na qual ambos têm seu lugar estável predeterminado).

Nesse sentido, é importante não confundirmos autoridade com autoritarismo.

Freire (2011, p.60) faz uma reflexão sobre a necessidade desse cuidado, salientando ainda sobre a tensão existente ao redor desse tema, e destaca:

É o meu bom senso que me adverte de que exercer a minha autoridade de professor na classe, tomando decisões, orientando atividades, estabelecendo tarefas, cobrando a produção individual e coletiva do grupo não é sinal de autoritarismo da minha parte. É a minha autoridade cumprindo o seu dever. Não resolvemos bem, ainda, entre nós, a tensão que a contradição autoridade-liberdade nos coloca e confundimos quase sempre autoridade com autoritarismo, licença com liberdade.

A responsabilidade em atuar quando se tem autoridade fica evidenciada. Em sala de aula, a autoridade precisa ser bem utilizada em prol do objetivo maior, que é o ensinar. Enquanto o autoritarismo propõe um alicerce baseado na força, a autoridade requer respeito. Quando isso não ocorre, as chances de problemas de aprendizagem ocorrer são maiores. Segundo Freire (2011, p. 67), o ato de ensinar pertence ao aluno e ao professor:

A nossa capacidade de aprender, de que decorre a de ensinar, sugere mais do que isso, implica a nossa habilidade de apreender a substantividade do objeto aprendido. A memorização mecânica do perfil do objeto não é aprendizado verdadeiro do objeto ou do conteúdo. Neste caso, o aprendiz funciona muito mais como paciente da transferência do objeto ou do conteúdo do que como sujeito crítico, epistemológicamente curioso, que constrói o conhecimento do objeto ou participa de sua construção. É precisamente por causa desta 
habilidade de apreender a substantividade do objeto que nos é possível reconstruir um mal aprendizado, em que o aprendiz foi puro paciente da transferência do conhecimento feito pelo educador.

A passividade é o que aborda Freire nessa passagem, não há uma relação automática, pelo simples fato de estarmos diante de humanos, o que não pode ser considerado como um mero instrumento de memorização. O que põe em risco inclusive o que está nesse trabalho, pois a ciência não é uma verdade absoluta e a certeza de hoje, poderá não fazer mais sentido amanhã quando tratamos de processo de ensino e aprendizagem.

O aluno não chega à escola sem um conhecimento prévio, que carrega suas relações sócio-históricas, construídas no ambiente em que vive. Para que a escola tenha sentido para esse sujeito, a mesma não poderá ignorar esse conhecimento prévio e válido. Nesse aspecto, Freire (2011, p. 120), destaca:

Sem bater fisicamente no educando o professor pode golpeá-lo, impor-lhe desgostos e prejudicá-lo no processo de sua aprendizagem. A resistência do professor, por exemplo, em respeitar a "leitura de mundo" com que o educando chega à escola, obviamente condiciona por sua cultura de classe e revela em sua linguagem, também de classe, constitui um obstáculo à sua experiência de conhecimento.

Para Wallon (1975, p. 370), o ensino em que o interesse do aluno vem à tona faz com que ele busque o conhecimento, independente da necessidade de expor os motivos desse saber: "A partir de objetos ou de situações que o tocam de perto, é necessário fazê-lo descobrir, gradualmente, o que também de perto se relaciona com seus interesses." Conseguir despertar no aluno, por meio de contextos do seu cotidiano, os conteúdos escolares, é essencial para que ele se dedique e busque aprimorar esses seus saberes.

\section{Teoria e pratica educativa}

Sobre teoria e prática educativa, Candau (2001, p. 67-68) nos demonstra que não há como pensarmos separadamente. A teoria explica e reflexiona sobre a prática, ao ponto de uma não substituir a outro, nem mesmo de uma ser mais importante que a outra:

A teoria e a prática educativa, neste enfoque, são consideradas o núcleo articulador da formação do educador, na medida em que os dois polos devem ser trabalhados simultaneamente, constituindo uma

RIAEE - Revista Ibero-Americana de Estudos em Educação, Araraquara, v.12, n.4 , p.2193-2209, out./dez. 2017. 
unidade indissolúvel. Há uma implicação mútua entre eles, superandose assim uma tendência muito encontrada nos cursos de Pedagogia e de Licenciatura que considera a prática educacional como separada das teorias pedagógicas.

É necessário o professor ter claro e aplicar em seu cotidiano laboral a ideia de que todo ser humano, em condições normais, é capaz de aprender, o que não significa aprender da mesma forma. Signos e métodos são absorvidos de modo diferente, por isso a importância do que Wallon (1975, p. 371) afirma: "Entre os seres humanos existem diferenças e é preciso ter em conta a maneira de reagir de cada um". Nesse sentido, conhecer o contexto em que vivem e suas realidades sociais são imprescindíveis ao professor.

Conforme Candau (2011), educar é também planejar, pois é por meio do planejamento que podemos organizar as aulas de acordo com as necessidades dos alunos, dessa forma, podemos proporcionar a eles significados aos conteúdos propostos:

$\mathrm{Na}$ verdade, o seu fazer pedagógico (o qual abrange "o que ensinar e como ensinar") deve se fazer articulado ao "para quem" e "para que", expressando a unidade entre os conteúdos teóricos e instrumentais dissociados integral ou parcialmente em muitas das práticas de formação existentes. Neste sentido, todos os componentes curriculares devem trabalhar a unidade teoria-prática sob diferentes configurações, para que não se perca a visão da totalidade da prática pedagógica e da formação como forma de eliminar distorções decorrentes da priorização de um dos dois polos (CANDAU, 2011, p. 69).

Nesse aspecto, Vigotski (2003, p. 98) chama a atenção para o papel que a escola desenvolve na avaliação e no reconhecimento das diferenças existentes entre os alunos e como a escola pode agir de modo mais perspicaz e justo:

A tarefa da escola não reside em medir todos os alunos com a mesma régua; pelo contrário, um dos objetivos da estruturação do meio social escolar consiste em obter a organização mais complexa, diversa e reflexível possível de seus elementos. Esses elementos não devem ser incompatíveis e devem concordar com o sistema. Em um sistema rico e flexível, as diferenças sexuais podem facilmente ser levadas em consideração durante a influência educativa. E como a premissa psicológica básica de nossos sistemas educativos é estabelecer na escola os vínculos que posteriormente serão necessários na vida, devemos impregnar de antemão a escola com uma rede dessas relações não sexuais, que depois serão imprescindíveis à vida. E isso pressupõe a mais ampla comunicação de ambos os sexos na escola como base do sistema educativo.

Muitos alunos saem da escola sem conhecer os conteúdos básicos para dar sequência à sua vida acadêmica, profissional, sem saber os valores que são essenciais 
nos processos de formação humana. Essa formação deficitária, tanto nos aspectos dos conhecimentos científicos como na formação humana tem ocupado o espaço escolar e, por vezes, é aceita como normal por essa comunidade.

\section{Política, mercado de trabalho e vida em sociedade.}

No questionário, os entrevistados puderam expor suas opiniões sobre o que pensam do papel da escola em ministrar temas como política, mercado de trabalho e vida em sociedade junto aos conteúdos tradicionais de cada disciplina. Os resultados demonstram que há total interesse por parte dos alunos sobre esses temas, demonstrando que o grupo não está preocupado apenas em deter conhecimentos que são abordados em vestibulares ou provas de ingresso ao Ensino Superior: temos 98\% das respostas positivas com relação à importância dos professores abordarem tais assuntos em sala de aula, conforme Gráfico 3.

Gráfico 3: Metodologias que mais contribuem para a aprendizagem, na concepção dos alunos

\section{Você acha importante os professores abordarem em sala de aula temas como política, mercado de trabalho e vida em sociedade?}

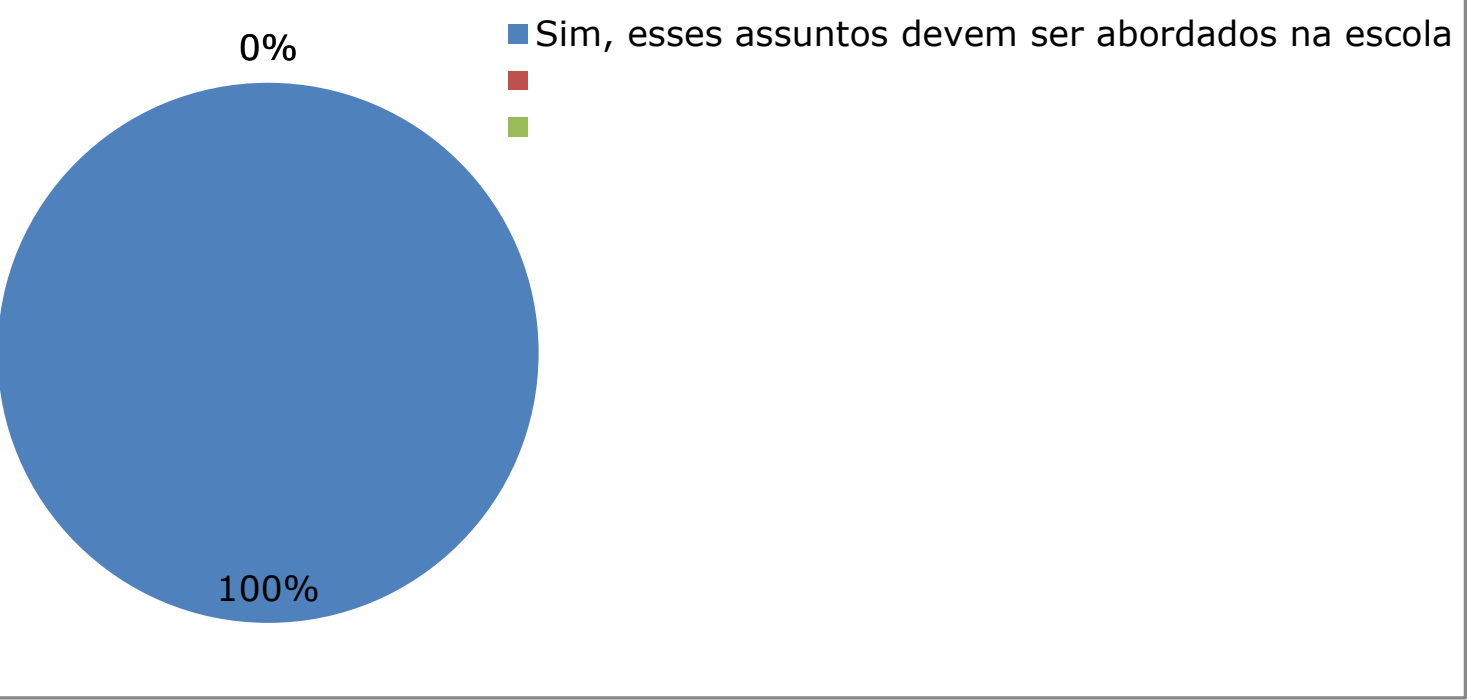

Fonte: Elaboração própriaa partir de dados da pesquisa.

RIAEE - Revista Ibero-Americana de Estudos em Educação, Araraquara, v.12, n.4 , p.2193-2209, out./dez. 2017. 
Como explica Arroyo (2011), nós professores precisamos romper com a educação bancária, que leva em consideração apenas uma feição do ensino. Para isso, é necessário que adotemos nova forma de educar e de nos relacionar com o ensino, o que significa, na percepção do autor (2011, p. 45),

Deixar de tratar os saberes humanos como apenas conteúdo, matérias escolares, temáticas, conhecimentos de nossa disciplina, de cada bimestre ou ano letivo, como precondição para passar de série, no concurso e no vestibular. Avançar revelando a nós mesmos e às crianças e adolescentes os sinais de humanização que aí apontam. Aprender a escutar esses sinais, a entender os processos como os seres humanos nos tornamos possíveis, nos desenvolvemos. Revelar os significados dados pela história. Cultivar essa sensibilidade nos educandos e em nós, no cotidiano da escola, nas relações entre as pessoas e gerações que ela propicia.

No desenvolvimento de um ensino mais humano, os diferentes espaços de aprendizagem e convivência do aluno necessitam ser considerados, por exemplo, a família. Ela tem uma relação muito semelhante com a escola, porque ambos têm como objetivo educar. Em contrapartida, essas duas instituições se relacionam de maneira distanciada.

Segundo Arroyo (2011, p. 44), na relação família e escola, “O máximo a que chegamos é a falar um pouco dos conhecimentos e competências, dos programas, das matérias, do livro didático e dos critérios de aprovação onde, em vez de encontrar-nos no que é comum, nos desencontramos". Vale enfatizar que cabe à escola o ensino formal e que a família pode contribuir, todavia é aconselhável que sua contribuição se realize mediante orientação por parte da escola; por isso, a importância do diálogo entre família e escola.

\section{Efetivação do ensino e da aprendizagem}

Para a efetivação dos processos do ensino e da aprendizagem, é necessário fazer uso de diferentes estratégias e metodologias em sala de aula, no intuito de contemplar as necessidades de cada um. O aprender é resultado da ação que o professor tem na sua atividade docente; o sucesso ou não do aluno depende muito dessa atuação e da interferência das relações socioculturais ao longo de sua formação:

$\mathrm{Na}$ verdade, o insucesso e o sucesso (escolar ou outro) não são nunca realidades objetiváveis, mas relação entre aspirações ou objetivos, por outro lado, e resultados obtidos por outro, relações essas que se desenvolvem como negativas ou positivas. Daí a persistente relação negativa entre objetivos visados na educação escolar e resultados 
obtidos remete-nos para a análise mais fina do porquê e do como dessa negatividade persistente, questionando necessariamente a adequação do modo de trabalhar escolar. Trata-se de analisar, em particular, a relação com o saber e a aprendizagem que a ação docente da escola consegue ou não gerar diante destes alunos ditos em insucesso e a análise dos seus processos cognitivos individuais no quadro do condicionamento dos contextos e pertenças socioculturais que são indissociáveis dos modos de aprender de todo e qualquer sujeito, incluído os "bem-sucedidos" (ROLDÃO, 2001, p. 126-127).

O ensino não pode se basear apenas nos conteúdos, tanto o aluno quanto o professor precisam sentir e vivenciar o aprendizado. Quando o aluno tem desejo de aprender e sente-se num espaço acolhedor, o processo de aprendizagem se efetiva. $\mathrm{O}$ ser humano é também um ser de emoção, e esta o acompanha ao longo de sua vida e interfere nas relações que ele tem, tanto no aspecto cognitivo como no afetivo. A construção da humanização do ser não desenvolve apenas o intelectual, mas também o emocional. Para Wallon (1975, p. 397), essa relação entre o cognitivo e o afetivo se desenvolve articulada e constantemente, sendo, assim, fundamental para os processos do ensino e da aprendizagem:

A vida afetiva apresenta certas particularidades essenciais que necessitam ser conhecidas por todos os que possam estar em relação com estas crianças ou adolescentes, a fim de que possam entender melhor a maneira como se processam estas relações de afetividade em relação ao seu desenvolvimento e de que maneira estas estão influenciando nos processos de ensino e da aprendizagem.

A escola precisa levar em consideração o emocional dos alunos. Muitas instituições se preocupam excessivamente com a formação intelectual, esquecendo que o aluno passa por mudanças, conflitos e transformações. As instituições de ensino e nós professores temos o compromisso de ajudar o aluno a compreender essa transformação e entender que ele é um sujeito que pensa, tem emoções e é dinâmico, pois, segundo Wallon (1975, p. 388), “o melhor ambiente é aquele em que as relações afetivas podem desenvolver-se em maior liberdade, diversidade e naturalidade." Isso requer um olhar educacional resiliente por parte do professor e demais profissionais da educação.

O professor necessita ir além dos conteúdos das disciplinas para atingir a essência da aprendizagem. A interação entre professores e alunos numa concepção de que ambos são seres completos, dinâmicos e multidimensionais é fundamental para os processos do ensino e da aprendizagem. Nessa direção, Vigotski (2003, p. 121) ressalta:

RIAEE - Revista Ibero-Americana de Estudos em Educação, Araraquara, v.12, n.4 , p.2193-2209, out./dez. 2017. 
A emoção não é uma ferramenta menos importante que o pensamento. A preocupação do professor não deve se limitar ao fato de que os alunos pensem profundamente e assimilem a geografia, mas também que a sintam. Por algum motivo esta ideia não passa pela nossa mente, e o ensino matizado por emoções é um raro hóspede entre nós. [O ensino], na maioria das vezes, está ligado ao carinho imponente que o professor sente por sua matéria, porém ele não conhece a forma de transmitir esse amor a seus alunos e, portanto, costuma ser considerado um extravagante.

Apenas dizer que precisa prestar atenção na aula porque isso é bom para o futuro não é o bastante, nem significativo para levar o aluno a se interessar pelos conteúdos escolares. Conforme Luckesi (2013, p. 28), "Não se pode fazer educação sem 'paixão"”. O que significa que nós professores precisamos gostar da nossa atividade docente e executá-la com amor. Por vezes, adotamos ações na escola sem ao menos nos questionarmos se isso é bom ou ruim para a educação. Outras tantas, adotamos caminhos mais curtos e fáceis sem nos preocuparmos se essa é a melhor estratégia. Por ocasiões, somos o maior exemplo de individualismo, pois adotamos critérios que facilitam apenas a nossa vida, desconsiderando o coletivo.

A falta de compromisso com o ser humano tem feito, muitas vezes, da educação apenas um instrumento para atender a demanda de uma minoria. Ser educador, na atualidade, é mais do que aceitar as regras impostas pelas instâncias superiores, é proporcionar ao aluno a transformação de sua vida e da sociedade em que faz parte. Todavia, não podemos ser ingênuos a ponto de acreditar que isso depende unicamente do professor, em virtude de que há a necessidade do trabalho coletivo entre gestão, equipe pedagógica e professores. Considerar o desenvolvimento humano com base em uma concepção multidimencional é fazer a interação entre o objeto de conhecimento e as diferentes dimensões humanas, considerando, destas, tanto seus aspectos cognitivo quanto os afetivos, os sensoriais e os sociais. Para que essa construção se efetive, é preciso ter um trabalho articulado e democraticamente construído entre todos que fazem parte da comunidade escolar.

Buscar a construção do trabalho pedagógico de forma coletiva pode ser o primeiro passo para transformar a escola em um espaço mais humano e democrático. Nós educadores temos um papel importante no processo de humanização da educação, desse modo, ao adotarmos uma determinada teoria metodológica, estamos nos colocando a favor ou contra o desenvolvimento humano. Muitas vezes, adotamos teorias baseadas no senso comum sem perceber as reais intenções que estas têm na 
construção da ideologia da classe dominante e no controle da sociedade. Dessa forma, reproduzimos velhos conceitos, valores e ideias que não contribuem para a transformação humana e social, pelo contrário, fazem com que a escola se desarticule de seus reais objetivos, que é educar para a formação integral do ser humano.

A sociedade humana precisa, urgentemente, encontrar caminhos para humanizar a convivência entre os homens; precisa criar espaços para que cada homem possa conhecer-se e saber-se capaz de ser o criador de sua existência, podendo, assim, sentir-se sujeito da realidade que o cerca e dela fazer parte, tornando-se consciente de que pode e deve transformar essa realidade, na direção incorporada pelo coletivo (FRANCO, 2008, p. 111).

Compreender como ocorrem os processos do ensino e da aprendizagem é uma das preocupações da educação. Muitas pesquisas questionam a fragmentação do conhecimento e apontam sérios problemas enfrentados pela educação em decorrência desse processo de ensino compartimentalizado, considerando-o um dos vilões da aprendizagem dos alunos. Sabemos que o conhecimento não se fragmenta, mas se complementa. No entendimento de Franco (2008, p. 41), é salutar para a educação empregar os conhecimentos das diferentes áreas no intuito de buscar melhorias no ensino:

Continuo pensando que a ciência da educação pode agregar conhecimento de outras áreas sem perder sua identidade ou fragmentar seu objeto, desde que mantenha definido seu olhar especialmente sobre o fenômeno educativo e que se utilize dos conhecimentos aceitos por outras ciências de forma crítica, por meio de filtros pedagógicos e de reconstrução de seu universo conceitual (e não de substituição).

Ao ser perguntado sobre a forma de aprendizado que mais lhe chama atenção, através da questão "Você acha que aprende mais quando:", tendo como opções de respostas: Lê sobre o assunto abordado em aula; O professor explica oralmente; Faz uma pesquisa com colegas; Outros; obtivemos os resultados conforme Gráfico 4. 
Gráfico 4: Metodologias que mais contribuem para a aprendizagem, na concepção dos alunos.

\section{Você acha que aprende mais quando:}

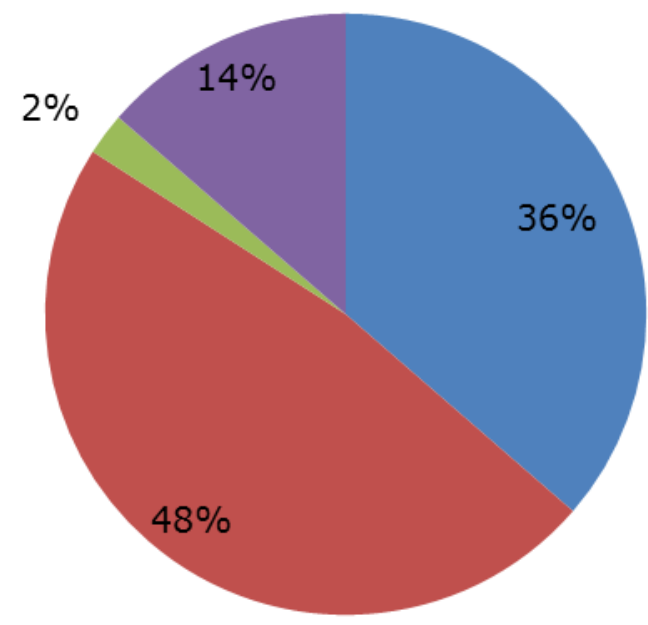

- Lê sobre o assunto abordado em aula - O professor explica oralmente

- Faz uma pesquisa com colegas

- Outro

Fonte: Elaboração própriaa partir de dados da pesquisa.

Em análise da questão do Grafico 4, verifica-se a indicação pela oralidade do professor como forma de aprendizado mais eficiente por parte do aluno, tendo $48 \%$ da preferência entre as alternativas. No entanto, o segundo lugar entre as alternativas demonstra que $36 \%$ dos entrevistados indicam que aprendem mais quando leem sobre o assunto. Em ambas as respostas, temos presentes modelos clássicos do ato de educar.

\section{Considerações finais}

Este artigo procurou dar voz ao estudante do Ensino Médio Integrado do IFC Campus Videira, no que diz respeito aos seus pensamentos sobre ensino e aprendizagem. Sendo assim, podemos destacar alguns pontos de vista desse importante agente do processo educativo: o estudante.

A frieza da relação professor-estudante cai por terra quando nenhum dos entrevistados optou pela "não interferência nos processos de ensino e da aprendizagem", quando perguntado que tipo de relação era mais propícia para a aprendizagem, onde a resposta "Representam um fator determinante nos processos de ensino e da aprendizagem" foi escolhida por $41 \%$ dos entrevistados. Isso nos demonstra que o 
estudante precisa sim de uma ponte que o leve até o professor, onde tal ponte só pode ser criada a partir da disposição do professor em construí-la.

Outro resultado surpreendente foi com relação à pergunta: "Você acha importante os professores abordarem em sala de aula temas como política, mercado de trabalho e vida em sociedade?". Em um mundo capitalista, onde o jovem parece se importar muito mais com as possibilidades de ganhar dinheiro a se preocupar com questões mais amplas, as respostas foram em peso para o "sim, esses assuntos devem ser abordados na escola", destruindo a ideia de que a escola deve unicamente preparar para o vestibular e não para a vida, e acabando também com a ideia que muitos adultos possuem acerca da alienação dos jovens com relação aos aspectos sociais, culturais e econômicos que os cercam.

Quando perguntados sobre o método que mais aprendem, nos deparamos em pleno século XXI com a força da oratória, onde $48 \%$ dos pesquisados informaram que aprendem quando o professor explica oralmente, desmistificando a ideia de grandes estruturas, necessidade de informatização para a realização desse processo sempre intrigante para os pesquisadores.

\section{REFERÊNCIAS}

ARENDT, Hannah. Entre o passado e futuro. Tradução de Mauro W. Barbosa de Almeida. 5. ed., 3. reim. São Paulo, Perspectiva, 2000.

ARROYO, Miguel G. Ofício de mestre: imagens e autoimagens 13. ed. Petrópolis: Vozes, 2011.

CANDAU, Vera Maria. Rumo a uma nova didática. 21. ed. Petrópolis: Vozes, 2011.

FRANCO, Maria Amélia do Rosário Santoro. Pedagogia como Ciência da Educação. 2. ed. São Paulo: Cortez, 2008.

FREIRE, Paulo. Pedagogia da autonomia: saberes necessários à prática educativa. 43. ed. São Paulo: Paz e Terra, 2011.

\section{LUCKESI, Cipriano Carlos. Avaliação da aprendizagem componente do ato} pedagógico. 1. ed. São Paulo: Cortez, 2011.

POLONIA, Ana da Costa; DESSEN; Maria Auxiliadora; SILVA, Nara Liana Pereira. O modelo bioecológico de Bronfenbrenner: contribuições para o desenvolvimento humano. In: DESSEN, Maria Auxiliadora; COSTA JUNIOR, Áderson Luiz (Org.). A Ciência do desenvolvimento humano: tendências atuais e perspectivas futuras. Porto alegre: Artmed, 2005. p. 71-89.

RIAEE - Revista Ibero-Americana de Estudos em Educação, Araraquara, v.12, n.4 , p.2193-2209, out./dez. 2017. 
ROLDÃO, Maria do Céu. A mudança anunciada da escola ou um paradigma de escola em ruptura? In: ALARCÃO, Isabel (Org.). Escolar reflexiva e nova racionalidade. 34. ed. Porto Alegre: Artmed, 2001. p. 115-134.

TARDIF, Maurice. Saberes docentes e formação profissional. 14. ed. Petrópolis: Vozes, 2012.

VIGOTSKI, Liev Semionovich. Psicologia pedagógica. Porto Alegre: Artmed, 2003.

WALLON, Henri. Psicologia e educação da infância. Lisboa: Editorial Estampa, 1975.

\section{Como referenciar este artigo}

SANTOS, Adelcio Machado dos.; et al. Ensino e aprendizagem na visão do estudante. Revista Ibero-Americana de Estudos em Educação, Araraquara, v. 12, n. 4, p. 2193 2209, out./dez. 2017. Disponível em: <http://dx.doi.org/10.21723/riaee.v12.n4.out./dez.2017.9211>. E-ISSN: 1982-5587.

Submetido em: 30/12/2016

Revisões requeridas: 26/01/2017

Aceita em: 13/03/2017 